\title{
Transcriptomic and Genomic Testing to Guide Individualized Treatment in Chemoresistant Gastric Cancer Case
}

\author{
Alexey Moisseev ${ }^{1, *}$, Eugene Albert ${ }^{1}$, Dan Lubarsky ${ }^{2}$, David Schroeder ${ }^{3}$ and Jeffrey Clark ${ }^{4}$ \\ 1 Institute for personalized medicine, I.M. Sechenov First Moscow State Medical University, 119048 Moscow, \\ Russia; mormegill@mail.ru \\ 2 Quantida, Inc., Newton, MA 02466, USA; dan@difive.com \\ 3 Wellesley Internal Medicine, 372 Washington St Ste 2, Wellesley Hills, MA 02481, USA; ds@wintmed.com \\ 4 Department of Hematology and Oncology, Massachusetts General Hospital, 55 Fruit Street Boston, MA \\ 02114, USA; Clark.Jeffrey@mgh.harvard.edu \\ * Correspondence: moisseevalexey@hotmail.com; Tel.: +7(926)1443639
}

Received: 25 February 2020; Accepted: 20 March 2020; Published: 23 March 2020

\begin{abstract}
Gastric cancer is globally the fifth leading cause of cancer death. We present a case report describing the unique genomic characteristics of an Epstein-Barr virus-negative gastric cancer with esophageal invasion and regional lymph node metastasis. Genomic tests were performed first with the stomach biopsy using platforms FoundationOne, OncoDNA, and Oncopanel at Dana Farber Institute. Following neoadjuvant chemotherapy, residual tumor was resected and the stomach and esophageal residual tumor samples were compared with the initial biopsy by whole exome sequencing and molecular pathway analysis platform Oncobox. Copy number variation profiling perfectly matched the whole exome sequencing results. A moderate agreement was seen between the diagnostic platforms in finding mutations in the initial biopsy. Final data indicate somatic activating mutation Q546K in PIK3CA gene, somatic frameshifts in PIH1D1 and FBXW7 genes, stop-gain in TP53BP1, and a few somatic mutations of unknown significance. RNA sequencing analysis revealed upregulated expressions of $M M P 7, M M P 9, B I R C 5$, and $P D-L 1$ genes and strongly differential regulation of several molecular pathways linked with the mutations identified. According to test results, the patient received immunotherapy with anti-PD1 therapy and is now free of disease for 2 years. Our data suggest that matched tumor and normal tissue analyses have a considerable advantage over tumor biopsy-only genomic tests in stomach cancer.
\end{abstract}

Keywords: gastric cancer; stomach adenocarcinoma; genomic test; molecular pathway analysis; immunotherapy; platform comparison; mutation; expression analysis; companion diagnostics

\section{Introduction}

Gastric cancer arises from epithelial lining of the stomach and is globally the fifth leading cause of cancer and the third leading cause of cancer death, making up $7 \%$ of cases and $9 \%$ of deaths [1]. Major classifications of gastric cancers (GCs) include histological classification by Lauren [2], where GCs are subdivided into intestinal and diffuse histotypes, and molecular classification recently proposed by The Cancer Genome Atlas (TCGA) consortium, which includes chromosomal instability, microsatellite instability (MSI), genomically stable, and Epstein-Barr virus (EBV) positive GC types [3]. EBV-positive subtype covers $\sim 9 \%-10 \%$ of all SC cases and is $\sim$ two times more frequent in male than in female patients. Diffuse and intestinal histotypes are presented in EBV-positive GCs in equal proportions [4]. In $30 \%-40 \%$ of the cases, this subtype overexpresses PD-L1 (ligand of Programmed Death-1) protein [5]. Enhanced expression of this biomarker may be associated with poor survival [6]. However, targeted 
PD-L1-specific immunotherapy showed 22\% objective response, $24 \%$ progression-free survival, and $69 \%$ overall survival 6 months after treatment [7].

The relatively high mortality in GC is linked with its strong potential to form metastases, mainly via epithelial-mesenchymal transition (EMT) process when epithelial cells lose their polarity and adhesion features while gaining migratory and invasive properties to become mesenchymal stem-like cells [8].

Prognosis in locally advanced and metastatic gastric cancer is dismal, with 1-year and 2-year progression-free survival of barely $50 \%$ and $25 \%$, respectively, and 5-year overall survival less than $10 \%$ [9]. Standard treatment for operable tumors consists of surgery with perioperative chemotherapy, the impact of radiotherapy being controversial. Recently, much effort was made to improve these dismal results with immune checkpoint inhibitors, mostly anti-PD-1 agents such as Pembrolizumab and Nivolumab. Several markers were explored to predict tumor response to these drugs, including, among others, tumor mutation burden and immunohistochemical tests for PD-L1. Unfortunately, apart from MSI, robust response predictors are lacking, and the optimal ways to incorporate immunotherapy into treatment algorithm are still under investigation [10-12].

We present a case of locally advanced gastric cancer treated with sequential chemotherapy, surgery, and immunotherapy; those prescriptions were guided by extensive genomic and transcriptomic testing. The genetic tests used were based on the gene panel exome sequencing [13,14], whole exome sequencing $[15,16]$, and a combination of RNA sequencing and whole exome sequencing [17,18], including molecular pathway annotation algorithms [19-21]. This allowed to compare different methods of annotating tumor-specific mutations and to implement gene expression-based personalized prioritizing of targeted therapeutics.

To our knowledge, this is the first report simultaneously using alternative comprehensive genomic, copy number variation, and transcriptomic approaches to characterize primary and metastatic disease in both tumor-only and matched tumor-normal modes to identify putative treatment options for the individual patient with GC.

\section{Case Presentation}

In October 2017, an 80-year-old Caucasian woman presented with gastric tumor that was incidentally discovered during routine ultrasonography. Biopsy showed moderately to poorly differentiated adenocarcinoma and HER2- and MSI-negative. Tests for H. pylori and EBV were negative. Staging with endoscopy, endoscopic ultrasonography, magnetic resonance imaging (MRI), and positron emission tomography-computed tomography (PET-CT) with 18F-fluoro-2-deoxy-D-glucose $\left({ }^{18}\right.$ FDG) revealed esophageal extension and suspicious regional lymph nodes, corresponding to clinical stage T3N1M0. The council decision was to start induction chemotherapy.

In November 2017, two courses of the FOLFOX regimen (Oxaliplatin + Fluorouracil/Leucovorin) were administered. The treatment was tolerated well, and the regimen was escalated to FLOT (Docetaxel, Oxaliplatin, and Fluorouracil/Leucovorin) by adding docetaxel; 4 cycles were given till February 2018. Toxicity was moderate, mainly neutropenia managed with filgrastim. Endoscopy after 4 cycles showed tumor shrinkage from 6 to $4 \mathrm{~cm}$ but no further regression after 6 cycles. In March 2018, partial proximal gastrectomy with esophageal resection and lymph node dissection was performed. Pathology reported viable residual tumor and one involved node, ypT3N1 (Figure 1). 

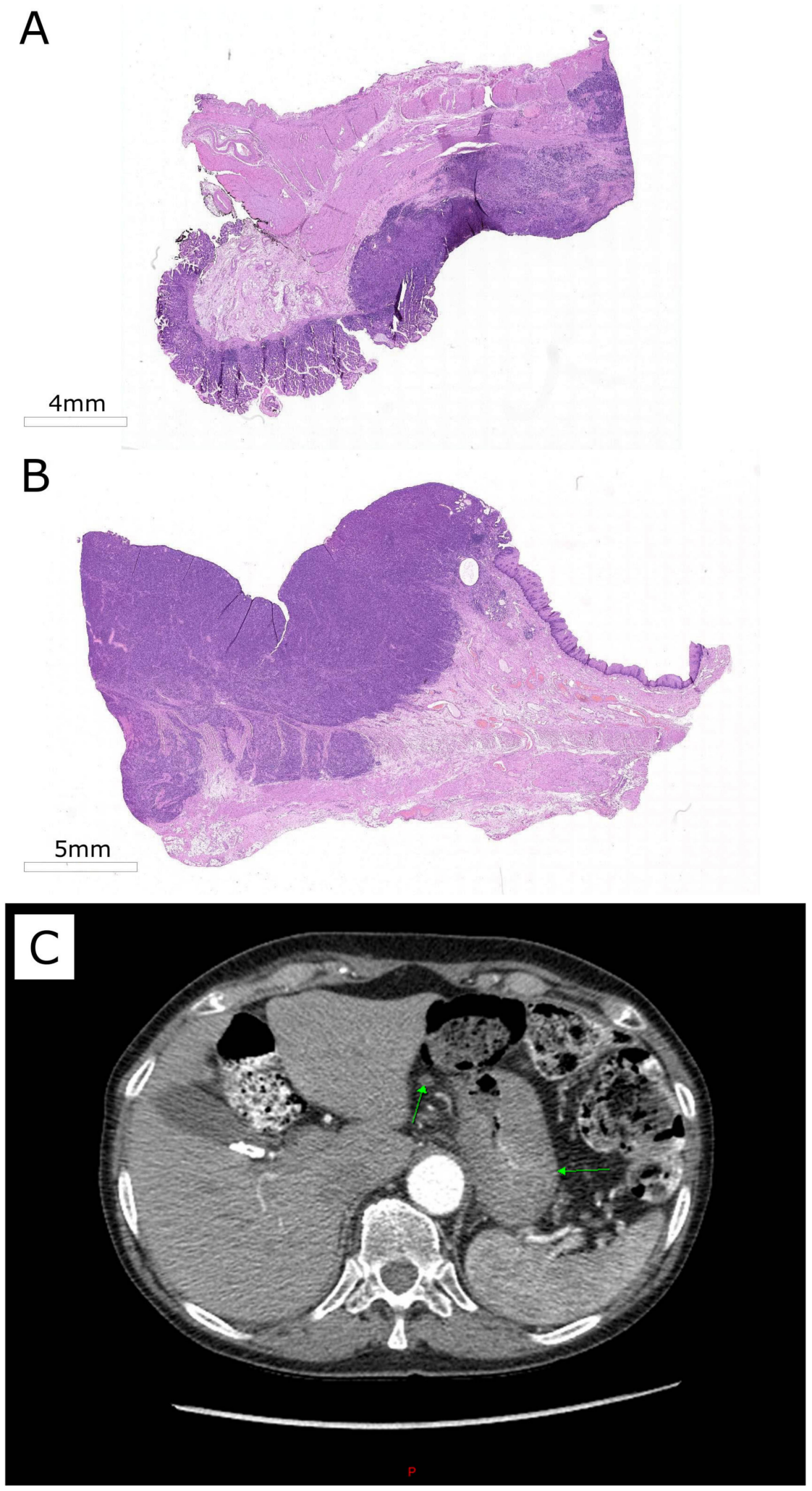

Figure 1. (A,B) Hematoxylin and eosin (H\&E) staining shows moderately to poorly differentiated adenocarcinoma. (A) Tumor removed from stomach. (B) Tumor removed from esophagus. (C) Baseline tumor appearance: primary gastric lesion (right arrow) and involved lymph node (left arrow).

According to current guidelines, further management would be adjuvant chemotherapy (4-6 cycles of FLOT or another regimen), but the patient's age and lack of clear benefit (downstaging) from 
the previous cytostatic treatment prompted us to seek alternative approaches. Another option could be observation until disease relapse, but the patient pursued an active treatment strategy. While she had a positive immunohistochemistry for PD-L1, this result was of limited practical value because this marker performs poorly in GC; moreover, at the time of treatment, immune checkpoint inhibitors like Pembrolizumab were not sufficiently studied and not approved for adjuvant therapy in gastric cancer. Along with PD-L1 positivity, patient's age and moderate mutation burden suggested benefit from immunotherapy, but the evidence was inconclusive [10-12].

To guide further therapy, the patient consented to enter a clinical trial NCT03724097 and underwent testing with Oncobox platform. Oncobox algorithm builds a personalized rating of target drugs for individual cancer patients. It is based on a simultaneous analysis of gene expression and molecular pathway activation in the patient's tumor and was shown to be effective in a retrospective cohort of gastric cancer patients [22], in several prospective advanced cancers cases [23-25], and in an ongoing prospective clinical investigation [26]. Gene expression profiling and whole exome sequencing was approved by institutional Review Board (IRB) at Clinical Center Vitamed, Moscow, Russia, protocol date 17 October 2016. According to test results (see below in details), further chemotherapy was omitted, and instead of it, adjuvant immunotherapy with anti-PD-1 antibody Pembrolizumab (Keytruda ${ }^{\mathrm{TM}}$ ) was prescribed. From June to December, the patient received 8 cycles. Adverse events were limited to hypothyroidism and mild fatigue. As of February 2020, she is free of disease with Karnofsky index 80\%.

\subsection{High Throughput Molecular Characterization of Tumor Biosamples}

Genomic tests were performed first with the stomach biopsy using commercial platforms Foundation One (F1) and OncoDNA, and copy number variation (CNV) was assessed using Oncopanel at Dana Farber Institute (Supplementary File 1) [19,27-47]. Following neoadjuvant chemotherapy, residual tumor was resected; the stomach and esophageal residual tumor samples were obtained and compared with the initial biopsy by whole exome sequencing and RNA sequencing-based molecular pathway analysis platform Oncobox (Obx). This allowed to identify the most probable individual case driver mutations using four alternative methods, to measure tumor mutational burden (TMB) using two methods, to establish gene expression levels of tumor marker genes, and to assess potential individual utility of immunotherapy using molecular pathway analysis.

\subsection{Tumor-Only and Tumor-Normal Modes for Finding Mutations in Tumor Biopsy and Surgery Biosamples}

WES-Obx pipeline was then applied to identify mutations using additional biosamples obtained from the same patient during surgical removal of the tumor. Two new tumor biosamples were obtained for stomach and esophageal localizations, respectively, matched by adjacent normal tissue samples. Totally, this made three tumor samples (initial biopsy, surgical stomach, and surgical esophageal) and two normal tissue samples (from stomach and esophageal tissues). Whole exome sequencing (WES) was done for all those biosamples (Table 1), and WES-Obx platform was used to identify mutations. Whole exome sequencing and gene expression data were deposited to NCBI Sequence Read Archive (SRA) under the accession numbers PRJNA545281.

Table 1. Statistics of genomic data obtained using sequencing-based cancer diagnostics platform Oncobox.

\begin{tabular}{lccccc}
\hline & Biopsy & $\begin{array}{c}\text { Normal } \\
\text { Stomach }\end{array}$ & Tumor-Stomach & $\begin{array}{c}\text { Normal } \\
\text { Esophagus }\end{array}$ & Tumor-Esophageal \\
\hline $\begin{array}{l}\text { Number of reads } \\
\text { Reads lengths }\end{array}$ & $222 \times 10^{6}$ & $227 \times 10^{6}$ & $236 \times 10^{6}$ & $139 \times 10^{6}$ & $232 \times 10^{6}$ \\
$\begin{array}{l}\text { Reads mapped on exons of } \\
\text { protein coding genes (\%) }\end{array}$ & $30-150$ & $30-150$ & $30-150$ & $30-150$ & $30-150$ \\
$\begin{array}{l}\text { Mean per-base coverage in } \\
\text { exons of protein coding genes } \\
\text { (standard deviation) }\end{array}$ & $147(283)$ & $112(211)$ & $99(196)$ & $65(155)$ & 40 \\
Reads in detected genes (\%) & 87 & 69 & 70 & 70 & $108(244)$ \\
\hline
\end{tabular}


In the previous tests comparing results of different platforms for the same tumor biopsy sample, we were able to identify mutations but could not find out if they were of germline or somatic origin. Now, we had reference normal patient's tissues and could distinguish somatic mutations. WES-Obx platform was applied in tumor-only mode for the sole tumor biopsy sample, thus giving an output of 502 germline + somatic mutations (Supplementary File 2), and in the mode of comparison with reference normal tissues (tumor-reference mode), thus providing 37 and 38 somatic mutations identified for surgical tumor samples of esophageal and stomach localizations, respectively. This dramatic difference in the number of mutations identified most probably pointed to the extremely high proportion (>90\%) of germline mutations and/or formalin fixation artifacts in the tumor-only mode of analysis. Most of mutations identified in tumor-reference mode were also identified in a tumor-only mode. Differences between somatic mutations found for the esophageal and stomach tumor localizations may be linked with different cellular compositions of those samples and overall patient's tumor heterogeneity. We, therefore, concluded that, in this case, tumor-reference mode of mutation search was more informative than a tumor-only mode. Final data indicate somatic activating mutation Q546K in the PIK3CA gene, somatic frameshifts in the PIH1D1 and FBXW7 genes, stop-gain in TP53BP1, and a few somatic mutations of unknown significance (Supplementary Files 1, 3 and 5).

\subsection{Tumor Mutational Burden Analysis}

Tumor mutational burden (TMB) is an emerging cancer biomarker that can influence therapeutic strategy, particularly in selection of immunotherapeutic treatment options [48]. In the F1 report, for the patient's primary tumor biopsy, TMB measured was 6 mutations per million nucleotide bases (per $\mathrm{mb}$ ). In WES-Obx analysis for the same biopsy sample, a similar figure was obtained of 7.8 mutations per mb. However, for the surgical tissue material, lower TMB values were obtained using WES-Obx platform: 5.7 and 5.0 for esophageal and stomach segments of tumor, respectively. These lower values were in a good agreement with extremely high degrees of surgical tumor tissue infiltration by blood cells (Figure 1), where only $\sim 50 \%$ were tumor cells according to histopathological expertise. Low proportion of tumor cells hampers robust identification of mutations due to low coverage of mutant alleles. However, this was not the case for the primary tumor biopsy, and we therefore used the TMB value of $6-7.8$ as the reference for the patient's tumor case.

\subsection{Analysis of Molecular Pathway Activation}

We examined the expression of genes, previously reported to be upregulated in gastric cancer. We identified significantly upregulated expression of $M M P 7, M M P 9, B I R C 5$, and PD-L1. To investigate functional interplay of the discovered driver gene mutations with the gene expression profiles, we analyzed differentially regulated molecular pathways using Oncobox pathway analysis software $[23,24]$. For every pathway, a pathway activation level (PAL) value was calculated [49] corresponding to degree of a pathway activation or downregulation in a tumor sample (biopsy, stomach, and esophageal localizations) in comparison to the normal stomach sample. Overall, PAL signatures strongly correlated among the three tumor samples analyzed (pairwise Spearman correlation coefficients 0.87-0.89). We then compared top 40 most strongly up- and downregulated molecular pathways in different tumor biosamples. Triple intersection showed that, among them, there were top common 31 upregulated and 21 downregulated pathways (Figure 2; Supplementary File 4).

Noteworthily, the second top upregulated molecular pathway was clinically actionable "Reactome PD1 signaling Pathway", which also contained mutated gene HLA-DRB1 (Figure 3). Upregulation of this pathway along with apparently high tumor infiltration by blood indicated abnormal activation of PD1/PD-L1 immunosuppression mechanisms and suggested potential benefit for the respective targeted immunotherapeutic treatment. 
A

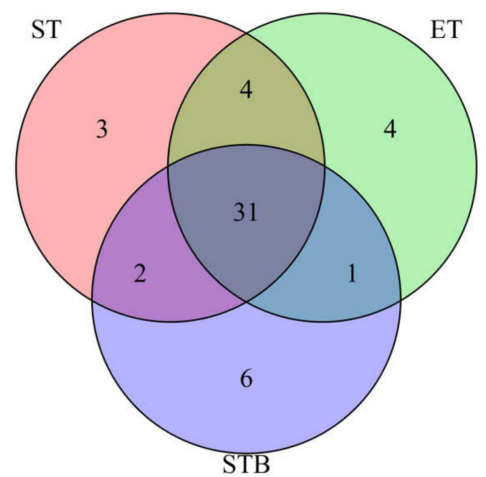

B

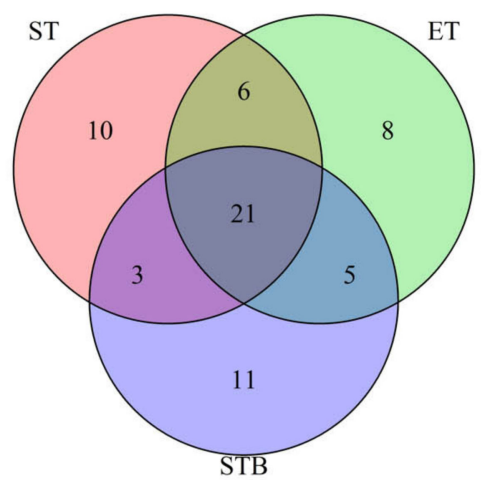

Figure 2. Overlap of top 40 activated or downregulated pathways for Stomach tumor (ST), Esophagus tumor (ET), and Stomach tumor biopsy (STB) samples: (A) upregulated pathways and (B) downregulated pathways.

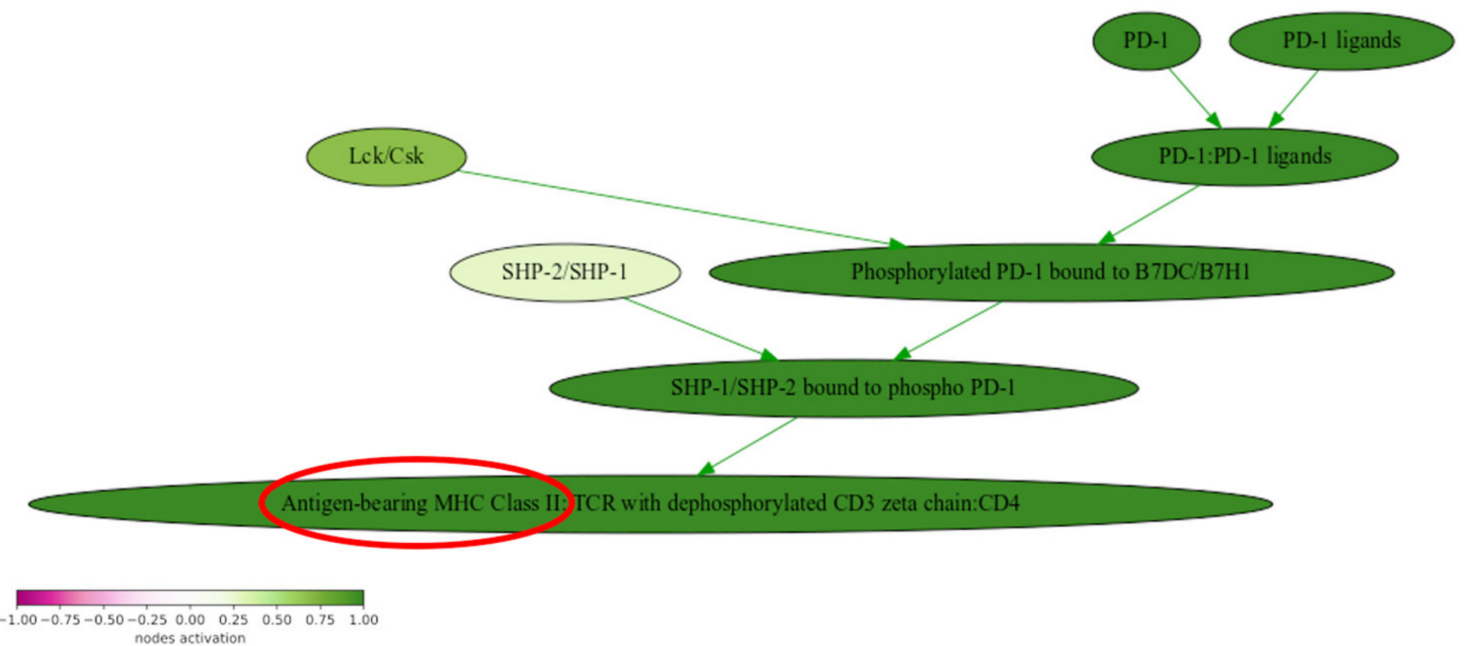

Figure 3. Pathway activation profile of the "Reactome PD-1 signaling Main Pathway" in a stomach tumor sample: mutated genes are circled in red.

\section{Discussion}

We compared whole exome sequencing profiles of tumor biopsy and two surgical tissue samples from different tumor sites (stomach and esophagus) in comparison with two adjacent normal tissue samples. We also compared performances of three commercial genetic diagnostics panels: FoundationOne, OncoDNA, and WES-Oncobox. Totally, we identified 502 mutations (Supplementary File 2) and found 3 major candidate genes-FBXW7, PIH1D1, and TP53BP1—that may serve as tumor suppressors and may contain inactivating mutations (Supplementary File 1). We found that these genes underwent copy-neutral loss of heterozygosity, which points to driver function of these mutations.

We detected significantly upregulated expression of $M M P 7, M M P 9, B I R C 5$, and PD-L1 in the patient's cancer samples. Increased expression of $P D-L 1$ was also associated with strong upregulation of the PD1 signaling molecular pathway, which supported the idea that immunotherapy could potentially be effective in this case. Taken together with intermediate tumor mutation burden value of $\sim 7$ mutations per $\mathrm{mb}$, these results supported including anti-PD1/PD-L1 therapy in the patient's treatment plan. Normal tissue was required for the pathway analysis, as Oncobox bioinformatical platform calculates pathway activation level in a tumor sample compared to a normal sample.

The genetic tests and advanced data analytic tools used here are still far less expensive than the therapeutics and/or clinical procedures applied. They also have a strong potential to decrease overall 
costs associated with the treatment by timely selecting the most appropriate therapeutic strategy. The prices for the genetic tests employed varied $\sim$ \$2000-6000 per test with the complete Oncobox test including drugs prioritization based on the combination of whole-exome sequencing and RNA sequencing data amounting to $\$ 3500$ [50].

\section{Conclusions}

In conclusion, the presented case report suggests that matched tumor and normal tissue analyses may have considerable advantage over biopsy-only genomic tests in selected cases. However, further prospective clinical investigations involving larger groups of patients with different malignancies are required to estimate clinical utility of such approach.

Supplementary Materials: The following are available online at http://www.mdpi.com/2227-9059/8/3/67/s1, Supplementary File 1: Technical comparison of DNA sequencing-based diagnostic platforms WES-Oncobox, OncoDNA, and FoundationOne; Supplementary File 2: Output of WES-Obx platform in tumor-only mode for the sole tumor biopsy sample: 502 germline + somatic mutations; Supplementary File 3: 386 mutations, common for all analyzed tumor samples. Supplementary File 4: Top 40 most strongly up- and downregulated molecular pathways. Supplementary File 5: 137 "off-target" genes in F1 sequencing results.

Author Contributions: Conceptualization, A.M. and J.C.; formal analysis, A.M., D.L., and E.A.; investigation (clinical management), A.M., D.S., and J.C.; data curation, A.M., D.L., and E.A.; writing—original draft preparation, A.M. and E.A.; writing-review and editing, J.C.; All authors have read and agreed to the published version of the manuscript.

Funding: This research received no external funding.

Acknowledgments: The authors are grateful to the patient for agreement to publication of the report.

Conflicts of Interest: The authors declare no conflict of interest. The Quantida, Inc. had no role in the design of the study; in the collection, analyses, or interpretation of data; in the writing of the manuscript, or in the decision to publish the results.

\section{References}

1. Stewart, B.; Wild, C.P. World Cancer Report 2014. Available online: http://publichealthwell.ie/node/725845 (accessed on 22 March 2020).

2. Lauren, P. The two histological main types of gastric carcinoma: Diffuse and so-called intestinal-type carcinoma. An attempt at a histo-clinical classification. Acta Pathol. Microbiol. Scand. 1965, 64, 31-49. [CrossRef] [PubMed]

3. Cancer Genome Atlas Research Network. Comprehensive molecular characterization of gastric adenocarcinoma. Nature 2014, 513, 202-209. [CrossRef] [PubMed]

4. Murphy, G.; Pfeiffer, R.; Camargo, M.C.; Rabkin, C.S. Meta-analysis shows that prevalence of Epstein-Barr virus-positive gastric cancer differs based on sex and anatomic location. Gastroenterology 2009, 137, 824-833. [CrossRef] [PubMed]

5. Garattini, S.K.; Basile, D.; Cattaneo, M.; Fanotto, V.; Ongaro, E.; Bonotto, M.; Negri, F.V.; Berenato, R.; Ermacora, P.; Cardellino, G.G.; et al. Molecular classifications of gastric cancers: Novel insights and possible future applications. World J. Gastrointest. Oncol. 2017, 9, 194. [CrossRef] [PubMed]

6. Wang, L.-A.; Wei, X.; Li, Q.; Chen, L. The prediction of survival of patients with gastric cancer with PD-L1 expression using contrast-enhanced ultrasonography. Tumor Biol. 2016, 37, 7327-7332. [CrossRef]

7. Akyala, A.I.; Verhaar, A.P.; Peppelenbosch, M.P. Immune checkpoint inhibition in gastric cancer: A systematic review. J. Cell. Immunother. 2018, 4, 49-55. [CrossRef]

8. Sun, F.; Feng, M.; Guan, W. Mechanisms of peritoneal dissemination in gastric cancer (Review). Oncol. Lett. 2017, 14, 6991-6998. [CrossRef]

9. Jim, M.A.; Pinheiro, P.S.; Carreira, H.; Espey, D.K.; Wiggins, C.L.; Weir, H.K. Stomach cancer survival in the United States by race and stage (2001-2009): Findings from the CONCORD-2 study. Cancer 2017, 123, 4994-5013. [CrossRef]

10. Brar, G.; Shah, M.A. The role of pembrolizumab in the treatment of PD-L1 expressing gastric and gastroesophageal junction adenocarcinoma. Therap. Adv. Gastroenterol. 2019, 12, 1756284819869767. [CrossRef] 
11. Kwok, G.; Yau, T.C.C.; Chiu, J.W.; Tse, E.; Kwong, Y.-L. Pembrolizumab (Keytruda). Hum. Vaccin. Immunother. 2016, 12, 2777-2789. [CrossRef]

12. Kugel, C.H.; Douglass, S.M.; Webster, M.R.; Kaur, A.; Liu, Q.; Yin, X.; Weiss, S.A.; Darvishian, F.; Al-Rohil, R.N.; Ndoye, A.; et al. Age Correlates with Response to Anti-PD1, Reflecting Age-Related Differences in Intratumoral Effector and Regulatory T-Cell Populations. Clin. Cancer Res. 2018, 24, 5347-5356. [CrossRef] [PubMed]

13. Fernandez Díaz, A.; Iranzo, V.; Calabuig Fariñas, S.; Jantus, E.; Cunquero Tomas, A.J.; Avila Andrade, C.; Sauvage, S.; Beniuga, G.; Camps, C.J. Clinical impact of using a deep genomic profile in carcinoma of unknown origin. Ann. Oncol. Off. J. Eur. Soc. Med. Oncol. 2018, 29 (Suppl 6). [CrossRef] [PubMed]

14. Torres, S.; González, Á.; Cunquero Tomas, A.J.; Calabuig Fariñas, S.; Ferrero, M.; Mirda, D.; Sirera, R.; Jantus-Lewintre, E.; Camps, C. A profile on cobas ${ }^{\circledR}$ EGFR Mutation Test v2 as companion diagnostic for first-line treatment of patients with non-small cell lung cancer. Expert Rev. Mol. Diagn. 2020, 1-8. [CrossRef] [PubMed]

15. Kamran, S.C.; Lennerz, J.K.; Margolis, C.A.; Liu, D.; Reardon, B.; Wankowicz, S.A.; Van Seventer, E.E.; Tracy, A.; Wo, J.Y.; Carter, S.L.; et al. Integrative Molecular Characterization of Resistance to Neoadjuvant Chemoradiation in Rectal Cancer. Clin. Cancer Res. 2019, 25, 5561-5571. [CrossRef]

16. Hart, M.R.; Biesecker, B.B.; Blout, C.L.; Christensen, K.D.; Amendola, L.M.; Bergstrom, K.L.; Biswas, S.; Bowling, K.M.; Brothers, K.B.; Conlin, L.K.; et al. Secondary findings from clinical genomic sequencing: Prevalence, patient perspectives, family history assessment, and health-care costs from a multisite study. Genet. Med. 2019, 21, 1100-1110. [CrossRef]

17. Buzdin, A.; Sorokin, M.; Garazha, A.; Glusker, A.; Aleshin, A.; Poddubskaya, E.; Sekacheva, M.; Kim, E.; Gaifullin, N.; Giese, A.; et al. RNA sequencing for research and diagnostics in clinical oncology. Semin. Cancer Biol. 2019. [CrossRef]

18. Buzdin, A.; Sorokin, M.; Poddubskaya, E.; Borisov, N. High-Throughput Mutation Data Now Complement Transcriptomic Profiling: Advances in Molecular Pathway Activation Analysis Approach in Cancer Biology. Cancer Inform. 2019, 18, 1176935119838844. [CrossRef]

19. Borisov, N.; Sorokin, M.; Garazha, A.; Buzdin, A. Quantitation of Molecular Pathway Activation Using RNA Sequencing Data. In Methods in molecular biology (Clifton, N.J.); Astakhova, K., Bukhari, S.A., Eds.; Springer Science + Business Media: New York, NY, USA, 2020; Volume 2063, pp. 189-206.

20. Zolotovskaia, M.A.; Tkachev, V.S.; Seryakov, A.P.; Kuzmin, D.V.; Kamashev, D.E.; Sorokin, M.I.; Roumiantsev, S.A.; Buzdin, A.A. Mutation Enrichment and Transcriptomic Activation Signatures of 419 Molecular Pathways in Cancer. Cancers 2020, 12, 271. [CrossRef]

21. Tkachev, V.; Sorokin, M.; Garazha, A.; Borisov, N.; Buzdin, A. Oncobox Method for Scoring Efficiencies of Anticancer Drugs Based on Gene Expression Data. In Methods in Molecular Biology (Clifton, N.J.); Astakhova, K., Bukhari, S.A., Eds.; Springer Science + Business Media: New York, NY, USA, 2020; Volume 2063, pp. $235-255$.

22. Sorokin, M.; Poddubskaya, E.; Baranova, M.; Glusker, A.; Kogoniya, L.; Markarova, E.; Allina, D.; Suntsova, M.; Tkachev, V.; Garazha, A.; et al. RNA sequencing profiles and diagnostic signatures linked with response to ramucirumab in gastric cancer. Mol. Case Stud. 2020, mcs.a004945. [CrossRef]

23. Poddubskaya, E.V.; Baranova, M.P.; Allina, D.O.; Smirnov, P.Y.; Albert, E.A.; Kirilchev, A.P.; Aleshin, A.A.; Sekacheva, M.I.; Suntsova, M. V Personalized prescription of tyrosine kinase inhibitors in unresectable metastatic cholangiocarcinoma. Exp. Hematol. Oncol. 2018, 7, 21. [CrossRef]

24. Poddubskaya, E.V.; Baranova, M.P.; Allina, D.O.; Sekacheva, M.I.; Makovskaia, L.A.; Kamashev, D.E.; Suntsova, M.V.; Barbara, V.S.; Kochergina-Nikitskaya, I.N.; Aleshin, A.A. Personalized prescription of imatinib in recurrent granulosa cell tumor of the ovary: Case report. Cold Spring Harb. Mol. Case Stud. 2019, 5, a003434. [CrossRef]

25. Poddubskaya, E.; Bondarenko, A.; Boroda, A.; Zotova, E.; Glusker, A.; Sletina, S.; Makovskaia, L.; Kopylov, P.; Sekacheva, M.; Moisseev, A.; et al. Transcriptomics-Guided Personalized Prescription of Targeted Therapeutics for Metastatic ALK-Positive Lung Cancer Case Following Recurrence on ALK Inhibitors. Front. Oncol. 2019, 9, 1026. [CrossRef]

26. Poddubskaya, E.; Buzdin, A.; Garazha, A.; Sorokin, M.; Glusker, A.; Aleshin, A.; Allina, D.; Moiseev, A.; Sekacheva, M.; Suntsova, M.; et al. Oncobox, gene expression-based second opinion system for predicting response to treatment in advanced solid tumors. J. Clin. Oncol. 2019, 37, e13143. [CrossRef] 
27. Adzhubei, I.; Jordan, D.M.; Sunyaev, S.R. Predicting functional effect of human missense mutations using PolyPhen-2. Curr. Protoc. Hum. Genet. 2013. [CrossRef] [PubMed]

28. Van der Auwera, G.A.; Carneiro, M.O.; Hartl, C.; Poplin, R.; Del Angel, G.; Levy-Moonshine, A.; Jordan, T.; Shakir, K.; Roazen, D.; Thibault, J.; et al. From FastQ data to high confidence variant calls: The Genome Analysis Toolkit best practices pipeline. Curr. Protoc. Bioinforma. 2013, 43. [CrossRef]

29. Lourenço, N.; Hélias-Rodzewicz, Z.; Bachet, J.-B.; Brahimi-Adouane, S.; Jardin, F.; Tran van Nhieu, J.; Peschaud, F.; Martin, E.; Beauchet, A.; Chibon, F.; et al. Copy-neutral loss of heterozygosity and chromosome gains and losses are frequent in gastrointestinal stromal tumors. Mol. Cancer 2014, 13, 246. [CrossRef]

30. Yeh, C.-H.; Bellon, M.; Nicot, C. FBXW7: A critical tumor suppressor of human cancers. Mol. Cancer 2018, 17, 115. [CrossRef] [PubMed]

31. Sailo, B.L.; Banik, K.; Girisa, S.; Bordoloi, D.; Fan, L.; Halim, C.E.; Wang, H.; Kumar, A.P.; Zheng, D.; Mao, X.; et al. FBXW7 in Cancer: What Has Been Unraveled Thus Far? Cancers 2019, 11, 246. [CrossRef] [PubMed]

32. Isono, M.; Niimi, A.; Oike, T.; Hagiwara, Y.; Sato, H.; Sekine, R.; Yoshida, Y.; Isobe, S.-Y.; Obuse, C.; Nishi, R.; et al. BRCA1 Directs the Repair Pathway to Homologous Recombination by Promoting 53BP1 Dephosphorylation. Cell Rep. 2017, 18, 520-532. [CrossRef]

33. Dobin, A.; Davis, C.A.; Schlesinger, F.; Drenkow, J.; Zaleski, C.; Jha, S.; Batut, P.; Chaisson, M.; Gingeras, T.R. STAR: Ultrafast universal RNA-seq aligner. Bioinformatics 2013, 29, 15-21. [CrossRef]

34. Croft, D.; Mundo, A.F.; Haw, R.; Milacic, M.; Weiser, J.; Wu, G.; Caudy, M.; Garapati, P.; Gillespie, M.; Kamdar, M.R.; et al. The Reactome pathway knowledgebase. Nucleic Acids Res. 2014, 42, D472-D477. [CrossRef] [PubMed]

35. Schaefer, C.F.; Anthony, K.; Krupa, S.; Buchoff, J.; Day, M.; Hannay, T.; Buetow, K.H. PID: The Pathway Interaction Database. Nucleic Acids Res. 2009, 37, D674-D679. [CrossRef] [PubMed]

36. Nakaya, A.; Katayama, T.; Itoh, M.; Hiranuka, K.; Kawashima, S.; Moriya, Y.; Okuda, S.; Tanaka, M.; Tokimatsu, T.; Yamanishi, Y.; et al. KEGG OC: A large-scale automatic construction of taxonomy-based ortholog clusters. Nucleic Acids Res. 2013, 41. [CrossRef] [PubMed]

37. Romero, P.; Wagg, J.; Green, M.L.; Kaiser, D.; Krummenacker, M.; Karp, P.D. Computational prediction of human metabolic pathways from the complete human genome. Genome Biol. 2005, 6, R2. [CrossRef] [PubMed]

38. Jiang, Y.; Qi, X.; Liu, X.; Zhang, J.; Ji, J.; Zhu, Z.; Ren, J.; Yu, Y. Fbxw7 haploinsufficiency loses its protection against DNA damage and accelerates MNU-induced gastric carcinogenesis. Oncotarget 2017, 8, 33444-33456. [CrossRef] [PubMed]

39. Nishimura, D. BioCarta. Biotech Softw. Internet Rep. 2001, 2, 117-120. [CrossRef]

40. Garazha, A.B.A.B.N.S.M. Quantitation of molecular pathway activation using RNA sequencing data. Methods Mol. Biol. 2019. [CrossRef]

41. Mao, J.-H.; Perez-Losada, J.; Wu, D.; Delrosario, R.; Tsunematsu, R.; Nakayama, K.I.; Brown, K.; Bryson, S.; Balmain, A. Fbxw7/Cdc4 is a p53-dependent, haploinsufficient tumour suppressor gene. Nature 2004, 432, 775-779. [CrossRef]

42. Sancho, R.; Jandke, A.; Davis, H.; Diefenbacher, M.E.; Tomlinson, I.; Behrens, A. F-box and WD repeat domain-containing 7 regulates intestinal cell lineage commitment and is a haploinsufficient tumor suppressor. Gastroenterology 2010, 139, 929-941. [CrossRef]

43. Squatrito, M.; Vanoli, F.; Schultz, N.; Jasin, M.; Holland, E.C. 53BP1 is a haploinsufficient tumor suppressor and protects cells from radiation response in glioma. Cancer Res. 2012, 72, 5250-5260. [CrossRef]

44. Zhang, S.; Tang, W.; Ding, G.; Liu, C.; Liu, R.; Chen, S.; Gu, H.; Yu, C. Variant TP53BP1 rs560191 G>C is associated with risk of gastric cardia adenocarcinoma in a Chinese Han population. Chin. J. Cancer Res. 2015, 27, 156-162. [CrossRef] [PubMed]

45. Shao, A.; Zheng, L.; Chen, S.; Gu, H.; Jing, H. p21, p53, TP53BP1 and $p 73$ polymorphisms and the risk of gastric cardia adenocarcinoma in a Chinese population. Biomarkers 2015, 20, 109-115. [CrossRef] [PubMed]

46. Hořejší, Z.; Stach, L.; Flower, T.G.; Joshi, D.; Flynn, H.; Skehel, J.M.; O’Reilly, N.J.; Ogrodowicz, R.W.; Smerdon, S.J.; Boulton, S.J. Phosphorylation-dependent PIH1D1 interactions define substrate specificity of the R2TP cochaperone complex. Cell Rep. 2014, 7, 19-26. [CrossRef] [PubMed]

47. Hudler, P. Genetic aspects of gastric cancer instability. Sci. World J. 2012, 2012, 761909. [CrossRef] [PubMed] 
48. Goodman, A.M.; Kato, S.; Bazhenova, L.; Patel, S.P.; Frampton, G.M.; Miller, V.; Stephens, P.J.; Daniels, G.A.; Kurzrock, R. Tumor Mutational Burden as an Independent Predictor of Response to Immunotherapy in Diverse Cancers. Mol. Cancer Ther. 2017, 16, 2598-2608. [CrossRef]

49. Buzdin, A.; Sorokin, M.; Garazha, A.; Sekacheva, M.; Kim, E.; Zhukov, N.; Wang, Y.; Li, X.; Kar, S.; Hartmann, C.; et al. Molecular pathway activation - New type of biomarkers for tumor morphology and personalized selection of target drugs. Semin. Cancer Biol. 2018. [CrossRef]

50. Oncobox. Available online: https://www.oncobox.com/ (accessed on 1 March 2020).

(C) 2020 by the authors. Licensee MDPI, Basel, Switzerland. This article is an open access article distributed under the terms and conditions of the Creative Commons Attribution (CC BY) license (http://creativecommons.org/licenses/by/4.0/). 